\title{
Applied research of data management in the education system for decision-making on the example of Al-Farabi Kazakh National University
}

\author{
Galimkair Mutanov ${ }^{1}$, Zhanl Mamykova ${ }^{1, *}$, Oksana Kopnova ${ }^{1}$, and Mukhtar Bolatkhan ${ }^{1}$ \\ ${ }^{1}$ Al-Farabi Kazakh National University, al-Farabi Ave. 71, 050040 Almaty, Republic of Kazakhstan
}

\begin{abstract}
In the context of the university digital transformation, the development of digitalization processes, it is necessary to introduce a data management culture. In most cases, this approach does not allow to see a big picture, as well as to identify "bottlenecks". There is a need to develop a unified data management strategy, which will assess the value of IT technology, and ensure the adoption of effective decisions. This article highlights the conceptual issues of data management strategies in higher education, using the example of the university. The place of the data processing strategy within the university's information space is considered a map model for analyzing key issues for decision making. The basic principles of organizing a data strategy for the university are determined. There is also considered an approach to designing and implementing an information and analytical system on the Microsoft Power BI cloud-based business analysis platform, which integrates all disparate data from university's corporate information systems and transactional data sources. The analysis of reports of key business processes of the university is carried out, in which the formulation of research questions is shown, and there have been given conclusions to these issues. Introduction of the information and analytical system in the contour of the university's corporate information system will contribute to the early identification of bottlenecks in the organization of the educational system and prompt decision-making in a systematic and comprehensive analysis of the main business processes of the educational organization through building a data map and visualizing all statistical reports.
\end{abstract}

\section{Introduction}

To make managerial decisions, the leader needs to operate with all data flows within the organization's information space. The sources of data for the information flows of space are corporate information systems. Each of them automates key business processes and often does not have consolidated data. There is a need to a qualitative improvement of the information and analytical support in educational institutions, including educational processes at all levels.

\footnotetext{
*Corresponding author: Zhanl.Mamykova@kaznu.kz
} 
The work of the information and analytical system (IAS) is based on the application of knowledge about the organization of the university's business processes, methods and models for working with data, data analysis and monitoring, data interpretation, so that IAS users have the opportunity to offer objective solutions to emerging issues, and adopt more objective management solutions.

IAS should allow to contribute to the implementation of such tasks at the university as improving the management of the university and the processes of scientific and educational activities (SEA); improving the quality of education; assistance in the tasks of advanced training of teaching staff and the effective use of pedagogical potential; identification of the reasons for educational failure; assessment of the effectiveness of educational complexes; control over the organization of the educational process.

The implementation of information and analytical support systems in the field of education involves systematic research and changes affecting all levels of education management.

Today, Kazakhstan education system does not have such a management document as "Data Management Strategy". There are only statistical reports in the current system for which there is no any visualization system or even an analytical module that would allow us to evaluate the development scenarios of the education system. In the world practice of the education system, there is no such a document. Now the CIO of the leading world companies speaks about the need to develop such a document and design a methodology for studying and using the data generated in the system and organization. It will save the company's significant financial resources when introducing new projects. Thus, in the digital transformation era and the data mining technologies development, there is a revision of decision-making processes by adding a process for treatment and managing data.

\section{Literature and systems review}

The system of information and analytical support in the field of education should fulfill a number of complex tasks aimed at the development of the education system in accordance with the target orientation and the current categorial work of educational institutions.

Articles [3-4] mention the work of Russian colleagues Mitin, A. and Falicheva, T. on the development of an Information and analytical system for monitoring the quality of professional training. The core of this IAS is a combination of two interconnected data warehouses: a knowledge base and a database of reference books about employees, students, employers and other quantitative indicators of the educational institution.

In Kazakhstan Information and analytical system developed by the Committee on Statistics of the Ministry of National Economy of the Republic of Kazakhstan focused on the provision of statistical data on various indicators of education, economy, services market, labor and employment innovations. This system also contains the ability to build analytical reports on selected indicators. The analysis of dynamic rows allows you to calculate the increase and growth rate, absolute growth, the average value of indicators in the dynamics, the rows tendency - trend, asymmetry and excess. [5].

Thus, from the systems review [1-17] we see that these software products contain summary statistical data on quantitative indicators. They focused on providing only key parameters of the education system and do not allow in-depth analysis. Presented systems are information databases, which provide information for analytical data processing. Another significant drawback of such systems is the lack of communication with the primary source of information, and as a result, the question arises of the relevance of the provided data. Indirect connections of the education development in these systems are not viewed. Built-in algorithms for data analysis in these systems are not obvious and therefore cause more 
questions than answers. They do not allow a detailed analysis of the data sources and to evaluate the entire depth of the analyzed situation.

To implement an information and analytical system, an environment is needed that would make it possible to combine data from disparate systems together, significantly reduce the labor costs of producing reports, and improve the quality of information for making strategic decisions. Such a function was taken over by business analytical systems (Business Intelligence or abbreviated BI-systems) developed on the basis of cloud platforms, which are designed to receive real-time information for making strategic decisions in real time. The following platforms are distinguished for processing and analyzing data and presenting them in as reports forms: Microsoft Business Intelligence; Oracle Business Intelligence; SAP Business Objects; QlikView; Qlik Sense; Deductor; Prognoz Platform. Analysis of these systems allow to conclude that the Microsoft Business Intelligence platform is best suited for the education system, due to the fact that it provides fast analysis of a large amount of data. It allows to visualize the results of processing a data array with the personalization capacity, supports the capacity to collaborate with data by placing data on an LDAP server, provides secure publication of dashboards and view them from any device with Internet access. It is a real-time reporting system, and it allows to work in groups with data and automatic data synchronization for all users.

The literature review of information systems and problems in data management allowed to determine the approach to conducting applied research on data management in the education system to make decisions by designing and developing an information and analytical support system using the example of a higher education institution to accumulate an array of information indicators in purpose to analyze contribution of all subjects of scientific and educational activities to the overall result of the university development strategy, depending on their role And objectively assess the compliance of their actual activities and the planned development of the required parameters.

\section{Methods of research and design of IAS}

The complex task of university management is to improve the quality of the scientific and educational process, which requires systematic and timely analysis of comprehensive and reliable information about the status of the university. The solution to this task is possible by introducing modern information technologies into the university management process and constantly improving them. Therefore, higher educational institutions are constantly searching for effective ways to manage scientific and educational activities (SEA), in connection with which the university's information infrastructure is developing.

The information infrastructure is a combination of solutions of own and local developments and forms the information space of the university. Own developments can be attributed information systems for the automation of educational activities, scientific work of students and faculty, the use of distance learning technologies, as well as indicators for the implementation of the indicative plan. Local developments present as solution of third-party and performs the functions of automating financial and economic activities, an electronic document management system, using management software to administer key resources and services, training software and IT service resource management software solutions.

Often, managers face with the problem of obtaining actual and reliable data, which is stored in disparate local systems of the university's information space. Structural departments heads face the same problem during the period of writing reports and various inspections aimed at education monitoring. The preparation of analytical reports takes a large amount of time and additional load on the teaching and support staff. Therefore, the need has ripened for the creation of information and analytical systems that allow to consolidate data of 
university information systems for the implementation of analytical management functions, identifying hidden patterns and making informed management decisions.

Figure 1 schematically shows the place of the information and analytical system (IAS) in the information space of the university.

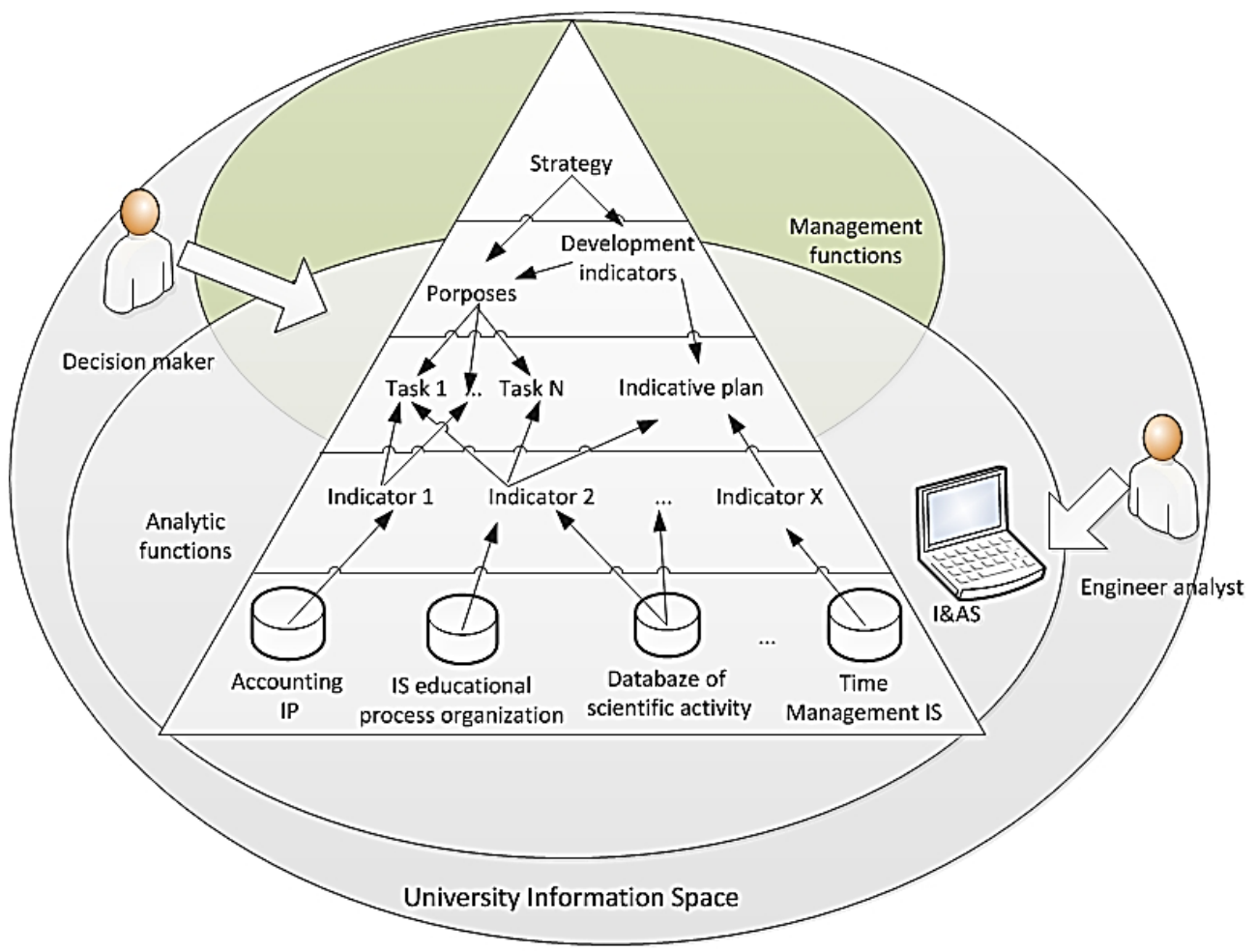

Fig. 1. Place of IAS in the information space of the university.

The information-analytical system (IAS) is a modern highly effective tool for supporting the adoption of strategic, tactical and operational management decisions, which is based on the visual and efficient provision of all the necessary data to the users responsible for analyzing the state of affairs and making managerial decisions.

The complex of information and analytical systems affects the entire management vertical of the university: corporate reporting, financial and economic planning and strategic planning.

The main purpose of IAS is a dynamic presentation and multivariate analysis of historical and current data, trend analysis, modeling and forecasting the results of various management decisions.

The purpose of developing IAS in the corporate information system (CIS) contour using the example of Al-Farabi Kazakh National University: to create an aggregating system for extracting data from various CIS sources, converting them and uploading them to storage, with the aim of constructing operational and intelligent data analysis for their effective perceptions to consumers.

The main features of the information and analytical system [9] should contribute to improving the quality of managerial decision-making through the application of rules, procedures and technologies to structure and automate information management processes. They must analyze data obtained from various sources (both internal and external). It should 
be a separate software product that functions separately from affiliated systems, but has twoway interaction with them.

To implement IAS, such methods and models as programming technologies, information systems developing, database theory, statistics, artificial intelligence, machine learning, data mining, economic and mathematical modeling were used.

The information and analytical system is a platform in which databases (MSSQL, MySQL, etc.) of disparate information systems of the organization's information infrastructure and transactional data sources are integrated. This data integration is accumulating at the cloud data warehouse level. The cloud architecture of the platform allows you to connect various data intelligent services like Microsoft Azure Learning, Analysis Services and Google Analytics. In order to use a systematic approach, as well as apply methods and models of economic and mathematical modeling and Intelligent Data Analysis, you can build visualization services and predictive analytics. Using Power BI, you can securely publish reports to your organization and set up automatic data updates so that all users receive up-to-date information.

Today, al-Farabi Kazakh National University (hereinafter KazNU) uses in the information infrastructure such information systems as in-house development systems (IS "UNIVER" - a system for automating the educational process, IS "Science" - a system for accounting for research activities, indicative planning and rating systems based on IS "UNIVER"); electronic document management system "Directum"; accounting and personnel accounting systems ("1C: Enterprise 8.2"); time attendance system "Perco 2.0"; system of statistical reporting of the contact center "VoIPTime Contact Center".

These information systems were integrated with the Power BI cloud platform, with the goal of building IAS in the CIS KazNU circuit (Figure 2).

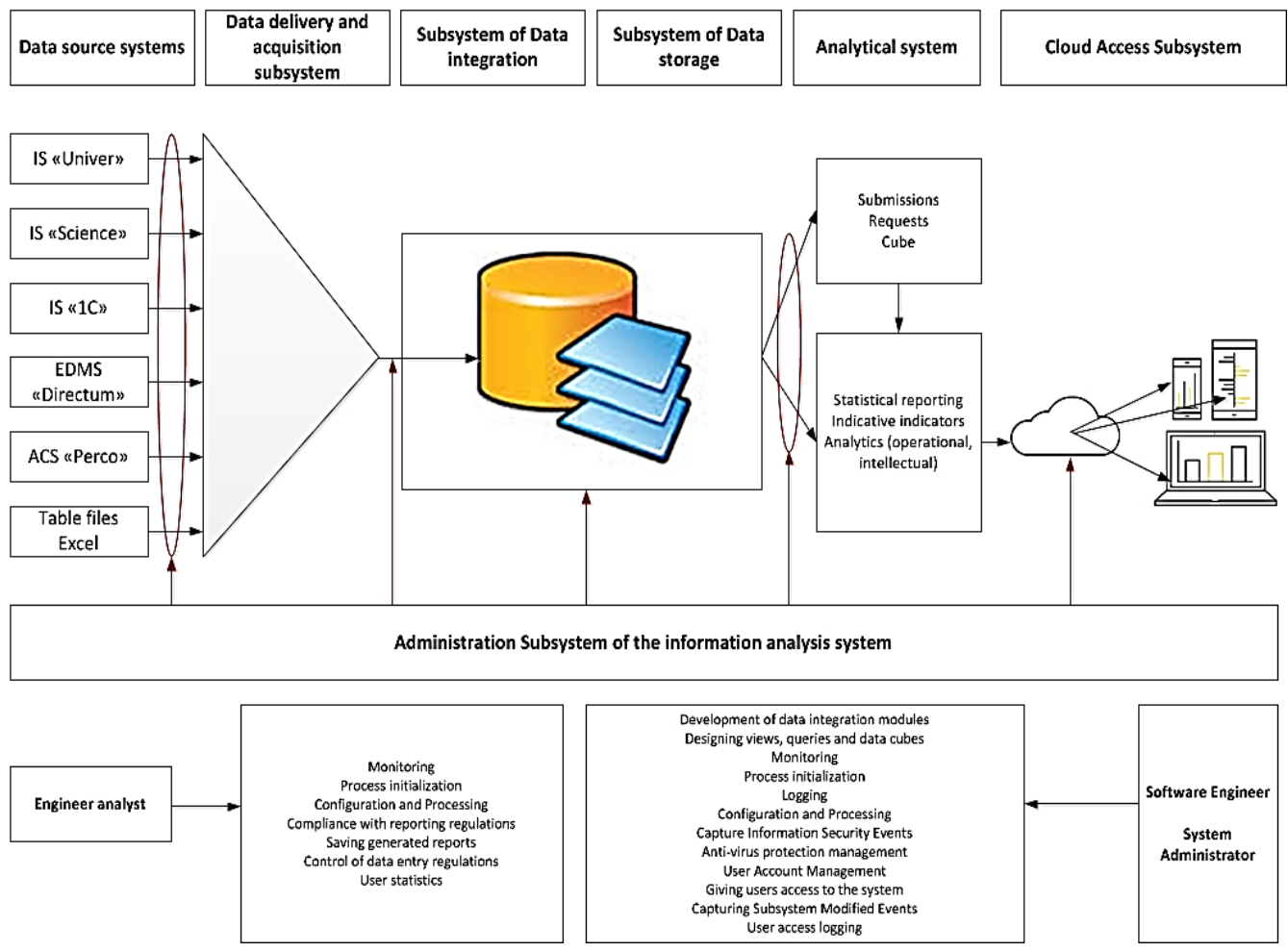

Fig. 2. Architecture of IAS CIS KazNU al-Farabi. 
In the context of the digital transformation of the university, the development of digitalization processes, it is necessary to introduce a culture of data management: collection, analysis, communication, identification of "bottlenecks", understanding, application, tools, management strategy, result orientation. It will assess the value of IT technology, and ensure the adoption of effective decisions.

There is a problem here - data management is still under development in many institutions. You need to start with simple tasks, and make efforts to build the entire model of data management of the learning process.

Thus, work is underway at Al-Farabi Kazakh National University to develop a data management strategy based on methods for determining how data is collected, stored, processed and used for various tasks of developing an education and decision-making system that allows you to build an information and analytical system, which integrates and accumulates disparate data of corporate information systems, provides an analysis of the state of scientific and educational activities of organizing education in the main areas of development, which are formalized as: the quality of educational services, research potential, innovative orientation, information and technical and technological infrastructure.

Without a data management strategy, an organization / university will be forced to engage in numerous data-related initiatives that are probably to be carried out by various business groups / departments. Initiatives can be analytics of data (based on statistical reports); business analytics (statistical and managerial reports, visualization, infographics); master data management (processing, storage, strategic indicators, reports).

In this regard, the authors of this article identified the basic principles of organizing a data strategy for a university, such as:

- Strategic priorities that are consistent with the University Development Strategy for the long term; the availability of skills and abilities to work with data.

- Data requirements: what data that creates value is needed; data type (structured, unstructured); data category (internal / external); data collection method; data quality and consistency.

- Data management: responsibility for: ensuring accuracy, completeness and relevance; data collection: collection method, integration mechanisms, permissions, GDPR security; data storage: reliability, security, trust; access to data: method, users, decision-makers, risks, security; data use: method (open / closed), data presentation format, legality.

- Technology for working with data: requirements for hardware and software; data collection; storage and organization of data; processing (analysis) of data (statistical methods, machine and deep learning algorithms) to extract ideas; information transfer (reports, visualization charts).

- Information on the adoption of data: the use of data as a predicting intelligence in making internal and external decisions; preparation and implementation of an action plan for the use of data and the introduction of change management; role of responsible executors.

- Analytics: development of dashboards and infographics; tuning data for the research questions; building predicting models; study of forecast data and refinement of data to obtain competitive advantages.

Based on these principles, the architecture of IAS was revised for the purpose to build a map of analysis of key issues, which is an analysis of 9 major university business processes, as shown in Figure 3.

As can be seen from Figure 3, it is proposed for each business process to identify 2-4 reports, which will be determined not only by the main parameters that reveal the report, but also by additional analysis parameters, such as age, academic degree, workload of teachers, etc., as well as input data on students (United National Test results, language of instruction, region, social status, achievements, etc.). For each report is expected, a formulating research question. 


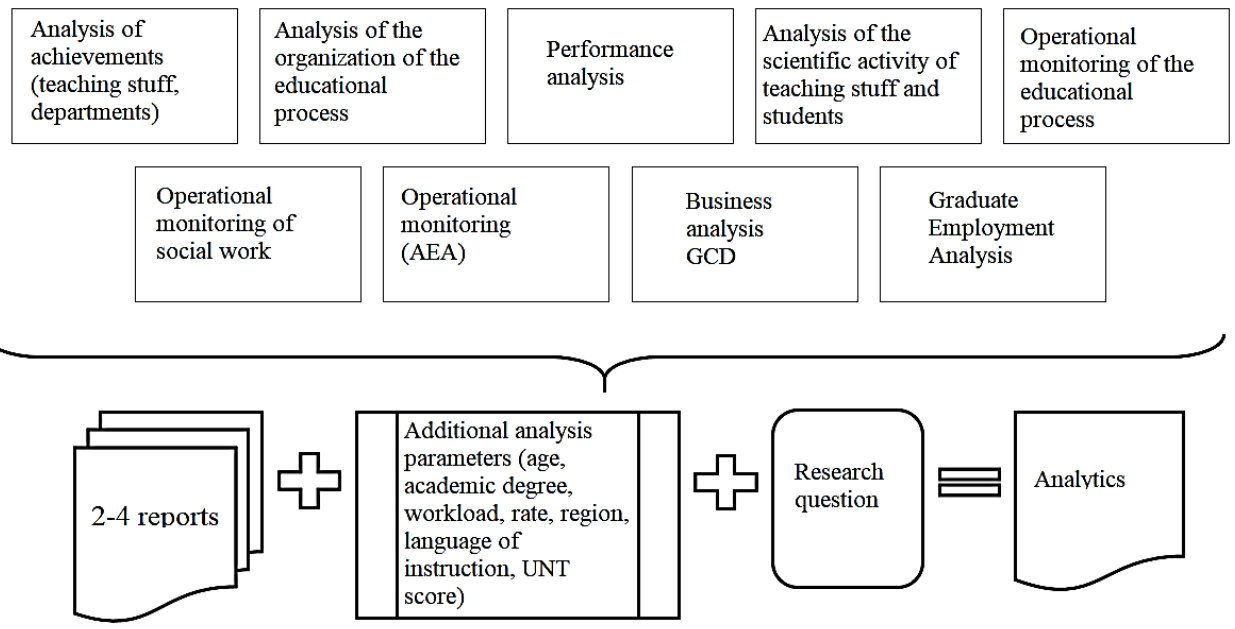

Identify "bottlenecks", understand the "reason", take prompt action, "predict" the situation

Fig. 3. Map model analysis of key issues.

Thereby, this approach will allow getting analytical reports and analytical indicators that will allow you to make the right managerial decision.

\section{IAS implementation, results}

To implement the approach to the development of analytical reports taking into account the concept of a data management strategy, we chose to building report "Achievements Analysis of teaching staff". For this analysis, the following data structure was determined, presented in Table 1.

Table 1. The structure of the data analysis of the achievements of teaching staff.

\begin{tabular}{l|l}
\hline \multicolumn{1}{c|}{ Parameter } & $\begin{array}{c}\text { The value for the observed } \\
\text { period }\end{array}$ \\
\hline Academic year & \\
\hline Faculty & \\
\hline The department & \\
\hline The teachers full name & \\
\hline Academic degree: (candidate of sciences, PhD, doctor of sciences) & \\
\hline Academic title: (associate professor, assistant professor, professor) & \\
\hline Position: (teacher, senior teacher, assistant professor, professor) & \\
\hline Full-time teacher or part-time & \\
\hline Age & \\
\hline Total Rating Score: & \\
\hline - Educational and methodical work (EMW) & \\
\hline - Scientific research work (SRW) & \\
\hline - Social upbringing work (SUW) & \\
\hline Load volume, rates & \\
\hline Teaching language: (Kazakh, Russian, English) & \\
\hline Number of articles in journals indexed by Scopus & \\
\hline
\end{tabular}




\begin{tabular}{l|l}
\hline The total value of the h-index & \\
\hline $\begin{array}{l}\text { Completeness and quality of loading (Educational-methodical } \\
\text { complex of disciplines, hereinafter EMCD) }\end{array}$ & \\
\hline Student performance in the disciplines studied & \\
\hline $\begin{array}{l}\text { Assessment of the quality of teaching according to the results of } \\
\text { the online questionnaire "Teacher through the eyes of students" }\end{array}$ & \\
\hline Number of violations in labor discipline & \\
\hline ASSESSMENT OF THE TEACHER'S ACTIVITY & \\
\hline
\end{tabular}

Based on these data, visual reports were constructed in IAS (Figure 4). The study and analysis of these reports allow you to answer the following questions:

- How does the academic degree and age of teaching staff affect the achievement of teaching staff in terms of GCD?

- How does the teacher's workload affect his achievements in the context of GCD?

- Is there an effect of age, academic degree, workload of teaching staff on the quality of the educational services provided (namely, student performance)?

- Is there a relationship between violation of labor discipline of faculty and student performance?

Analysis of the data on the achievements of faculty members is carried out on the example of the Department of Physics and Technology of the Faculty of Physics and Technology of al-Farabi Kazakh National University. For consideration, 77 teachers of the department were accepted, of which 36 are employees under 35 years old, 24 are employees from 35 to 49 years old, 7 are employees from 50 to 63 years old and 10 are employees over 63 years old. The analysis of the data presented in table 2 showed that mainly employees aged 35-49 years are engaged in scientific activity (107.54 is the average index of achieving the goal of scientific and research work). This is the age of doctoral students or doctors of science who have the most experience in writing scientific articles. The second indicator is for employees over 63 years old ( 45.84 is the average goal achievement index). These are retirement age employees already held in the profession, who most often have a scientific degree and are engaged in scientific activities more professionally and systematically. The lowest SRW indicator is for employees under 35 years old (19.07 is the average index for achieving a goal). These young employees have recently completed a master's degree or have entered doctoral studies. They do not yet have the skills to work on scientific projects and scientific articles. This analysis shows that age, in the context of the steadiness of employees, affects the achievements of faculty members in scientific and educational activities. So, the results show that the SRW rate for graduate students is 9 times higher than for those who do not have a degree. This is natural, because employees with a degree are leaders of doctoral students, undergraduates and graduates, and they have more opportunities to participate in scientific projects.

Table 2. Indicators of achievement of teaching staff depending on age.

\begin{tabular}{c|c|c|c|c|c}
\hline \multicolumn{2}{c|}{} & $\begin{array}{c}\text { under 35 } \\
\text { years old }\end{array}$ & $\begin{array}{c}\text { from 35 to 49 } \\
\text { years old }\end{array}$ & $\begin{array}{c}\text { from 50 to 63 } \\
\text { years old }\end{array}$ & $\begin{array}{c}\text { over 63 years } \\
\text { old }\end{array}$ \\
\hline \multicolumn{2}{c|}{ Number of teachers } & 36 & 24 & 7 & 10 \\
\hline \multirow{2}{*}{$\begin{array}{c}\text { Average Goal } \\
\text { Achievement } \\
\text { Index }\end{array}$} & EMW & 29 & 45,27 & 31,69 & 283,69 \\
\cline { 2 - 6 } & SRW & 19,07 & 107,54 & 29,64 & 45,84 \\
\cline { 2 - 6 } & SUW & 98,58 & 35,87 & 35,53 & 1,11 \\
\hline
\end{tabular}

According to the results of the analysis, according to the data in Table 2, it can be concluded that teachers over 63 years of age pay great attention to EMW, but are not at all interested in SUW. Employees in the category of 50-63 years evenly distribute their 
employment in all three areas of work (EMW, SRW, SUW); employees of the category 3549 years old are mainly engaged in research work. Teachers under the age of 35 are mainly involved in SUW. Thus, we can conclude that it is necessary to evenly redistribute the efforts of all categories of teachers in all three areas of scientific and educational activities.

Academic degree of teacher is also important in analyzing the achievements of faculty. At the Department of Plasma Physics and Computer Physics, 35\% of the composition has a candidate, doctor of science or PhD degree. Comparative characteristics of the indicators of the teaching staff with and without a degree presented in table 3 . The average index of achievements of doctors of sciences in EMW and SRW (10.23 and 1.53, respectively) significantly exceeds the indicators of teachers without a degree, which is explained by their experience in writing scientific papers and long teaching experience. At the same time, they are less active in upbringing work (0.12), spending most of their efforts on scientific work and teaching. The indicators of $\mathrm{PhD}$ and candidates of science in SRW (6.0 and 11.44, respectively) significantly exceed the indicators of teachers without a degree. This is due to their hard work in this direction during their studies in doctoral and postgraduate studies. At the same time, the SAR indicators are approximately equal (1.23 and 1.26, respectively).

Table 3. Analysis of the specific gravity of the achievements of faculty, depending on the degree of

\begin{tabular}{c|c|c|c}
\hline $\begin{array}{c}\text { Average Goal Achievement } \\
\text { Index }\end{array}$ & PhD / no degree & Candidate / no degree & Doctor / no degree \\
\hline EMW & 1,23 & 1,26 & 10,23 \\
\hline SRW & 6,00 & 11,44 & 10,53 \\
\hline SUW & 0,26 & 0,45 & 0,12 \\
\hline
\end{tabular}

To determine the impact of the teaching load on teaching staff on the GCD indicators, we examined the values of the indicators of teachers working part-time (from 0.25 to 1 ) and fulltime (from 1 and above). A comparative description of the average indicators of the Goal Achievement Index for EMW, SRW and SUW for indicative questionnaires of teaching staff is presented in table 4. According to the results of the analysis, it was found that the indicators of the achievement index of the goals for the EMW, SRW and SUW of full-time teachers significantly exceed the indicators of part-timers. The main place of work of full-time employees is KazNU, and they are more interested in working at the department and with students. They also have more work experience than new employees and doctoral students working part-time.

Table 4. Comparative analysis of the achievements of teaching staff in the context of the pedagogical load.

\begin{tabular}{c|c|c}
\hline Average Goal Achievement Index & Full-time & Part-time \\
\hline EMW & $94,89 \%$ & $5,49 \%$ \\
\hline SRW & $72,54 \%$ & $20,47 \%$ \\
\hline SUW & $110,10 \%$ & $14,97 \%$ \\
\hline
\end{tabular}

Comparative characteristics of the faculty indicators for the teacher stuff by academic degree depending on the EMW; Assessment according to the results of the questionnaire "Teacher through the eyes of students" and student performance are presented in table 5 . When analyzing the definition of the quality of educational services (student performance), it was found that doctors of science have the lowest student performance $(76,98)$, because they are stricter and more responsible in relation to educational activities. The results of the remaining categories of teachers do not have a pronounced dependence on these indicators. Consequently, the degree of teaching staff does not greatly affect student performance; it 
depends more on the personal and organizational qualities of the teacher [18].

The analysis of data on recorded violations of labor discipline for the 2018-2019 academic year for violations in this department did not reveal a definite effect on student performance indicators. Thus, we can conclude that there is no relationship between the violation of the labor discipline of faculty and student performance.

Table 5. Comparative characteristics of teaching stuff indicators.

\begin{tabular}{l|c|c|c|c}
\hline & Candidate & Doctor & PhD & No degree \\
\hline $\begin{array}{l}\text { The average index of achievement } \\
\text { of the goal on URM, \% }\end{array}$ & 37,59 & 305,53 & 36,6 & 29,87 \\
\hline $\begin{array}{l}\text { Assessment according to the results } \\
\text { of the survey "Teacher through the } \\
\text { eyes of students", \% }\end{array}$ & 4,56 & 4,69 & 4,71 & 4,66 \\
\hline Student performance, \% & 80,39 & 76,98 & 82,87 & 82,83 \\
\hline
\end{tabular}

Figure 4 presents a visual report on the analysis of the achievements of teaching staff implemented in the information and analytical system of KazNU ima.al-Farabi based on the cloud-based business analysis platform PowerBI.

\section{Report Date \\ 26 февраля 2020 \\ Analysis of teaching stuff achievements}

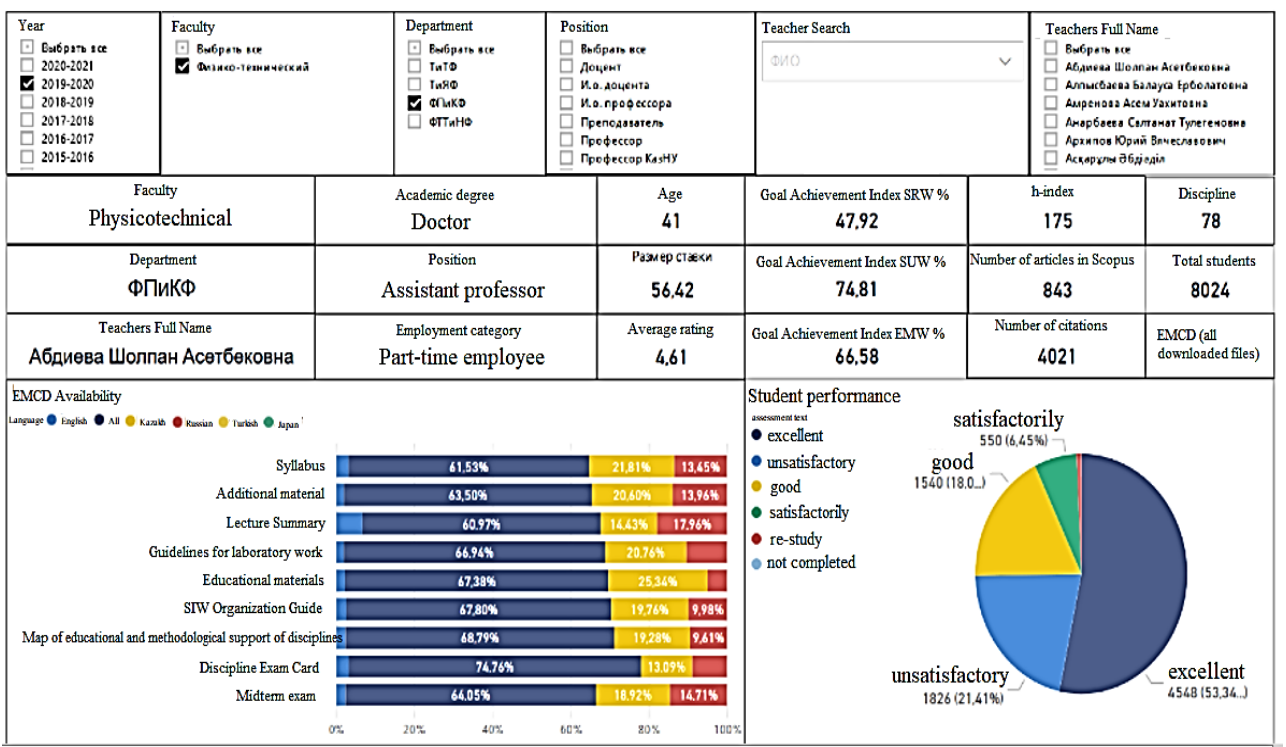

Fig. 4. Visual report on the analysis of the achievements of teaching staff on the example of IAS alFarabi KazNU

According to the results of the analysis of the teaching-stuff achievements, it should be concluded that much attention needs to be paid to the uniform distribution of the efforts of teachers of all age categories and degree of steadiness in all three areas of GCD to increase the overall level of teachers' skills. At the same time, great attention should be paid to the formation of the teaching staff from among regular staff, showing the best results and striving to improve the level of teaching, scientific and educational work. 


\section{Conclusion}

In this article the issue of developing a data management strategy for a university that allows to research data management issues and develop data management procedures is considered. An approach to designing and implementing IAS on the Microsoft Power BI cloud-based business analysis platform, which integrates all disparate data from university's corporate information systems and transactional data sources, is considered. The analysis of reports of key business processes of the university was carried out, in which the formulation of research questions was shown and given conclusions on these issues.

The approach used by the authors in the article to applied data research in the education system using the example of Al-Farabi Kazakh National University can be scaled to any organization that has a corporate information system consisting of its own and local developments of information systems and wishing to conduct a deeper analysis of activities organizations to make the right strategic decisions.

The economic effect of the introduction of such a system is: early identification of bottlenecks in the organization of the education system, operational decision-making; in a systematic and comprehensive analysis of the main business processes of the organization of education, through the construction of a data map and visualization of all statistical reporting, using data mining algorithms, thereby contributing to the digital transformation of the main business processes of the education system.

\section{References}

1. L. Dallemule, T. Deivenport, Harvard business review (Russia), 49-57, (2018)

2. Ministry of education and science of Perm Krai, Unified information and analytical system (UIAS) http://edustat.iro.perm.ru/

3. A. I. Mitin, T. A. Filicheva, G. V. Plekhanov Russian University of Economics, 4 (99), 46-51 (2013)

4. T. A. Filicheva, Information-analytical methods of monitoring the quality system of training managerial personnel, http://www.vivakadry.com/87.htm

5. Committee on Statistics Ministry of National Economy of the Republic of Kazakhstan, https://taldau.stat.gov.kz/

6. D. Isaev, Analytical Information Systems (Training Manual), 60 (State University, Moscow, 2008)

7. B. Minto, The Pyramid Principle: Logic in Writing and Thinking (Pearson Education Limited, United Kingdom, 2009)

8. K. E. Wiegers, Software Requirements Second Edition Practical techniques for gathering and managering requirements throughout the development cycle (Microsoft Press, 2014)

9. E. M. Rasiel, P. N. Friga, The McKinsey Mind Understanding and Implementing the Problem-Solving Tools and Management Techniques of the World's Top Strategic Consulting Firm (McGraw-Hill, 2009)

10. A. L. Dyckhoff, Action research and learning analytics in higher education (2014)

11. P. Arroway, G. Morgan, M. O'Keefe, R. Yanosky, Learning Analytics in Higher Education (Educause center for analysis and research, 2016)

12. V. L. Uskov, J. P. Bakken, A. Shah, T. Krock1, A. Uskov, J. Syamala, R. Rachakonda, Springer International Publishing AG, part of Springer Nature, 3, 3-16 (2019)

13. E. Mishchenko, P. Monastyrev, O. Evdokimtsev, IOP Conference Series: Materials Science and Engineering, 463 (2018)

14. K. Reda, Ch. Tantipathananandh, A. Johnson, J. Leigh, T. Berger-Wolf. IEEE Symposium on Visualization, 3, 1061-1070 (2011) 
15. T. N. Dang, N. Pendar, A. G. Forbes, Computer Graphics Forum, 61-69 (2016)

16. B. Bach, P. Dragicevic, D. Archambault, C. Hurter, S. Carpendale, Computer Graphics Forum, 36, 6, (2017)

17. A. J. Pretorius, I. A. Khan, R. J. Errington, Computer Graphics Forum, 36, 46-63 (2016)

18. Abdrakhmanova, M., Mutanov, G., Mamykova, Z., \& Tukeyev, U. Springer, Cham.G. (2018, September). DOI: 10.1007/978-3-319-98443-8_32 